\title{
Study and mitigation of epistemological obstacles in the technological disciplines of higher education in Madagascar: Case of industrial technical drawing
}

\author{
Ulrich Canissius $^{1 *}$, Abdoulaye Anne ${ }^{2}$ \\ ${ }^{I}$ Laboratoire de Mécanique et de Métrologie,École Normale Supérieure pour l'Enseignement Technique \\ (ENSET), Université d'Antsiranana, B.P.O, Antsiranana 201, Madagascar
}

${ }^{2}$ Département des fondements et pratiques en éducation, Faculté des sciences de l'éducation, Université Laval, Québec (Québec) G1V 0A6, Canada

*Corresponding Author: Ulrich Canissius, Laboratoire de Mécanique et de Métrologie,École Normale Supérieure pour l'Enseignement Technique (ENSET), Université d'Antsiranana, B.P.O, Antsiranana 201, Madagascar

Abstract: In this paper, we provide an element of response, from a conceptual and material point of view, to the problem encountered in the teaching-learning of technical drawing at the École Normale Supérieure pour l'Enseignement Technique - ENSET of the Antsiranana University in Madagascar.

After analyzing and discussing the results of measurements taken during field observations, we adjusted the teaching-learning system, through reference, theoretical and conceptual frameworks adapted and adopted following the literature review.

With this work, we present a new way of apprehending the learning object, in the new era through computer science which is part of socio-emotional mediation, and which will meet certain criteria of attraction social, modernization and creation inducing a stable scientific culture of the population involved.

Keywords: training of trainers, technical education, techno-didactics, technical drawing, educational modernization

\section{INTRODUCTION}

In the past five years, ENSET has experienced a drop in the number of student teachers in the mechanical engineering department, the subject of a question in teaching practice supposedly uncertain and unsuitable for the present era. Our ambition is to invest in the search for certain elements blocking the teaching-learning of technological sciences, the case of technical drawing, which is the basis of all industrial and civil engineering construction work on which students approach less and the reason a strong presence of lexical and syntactic errors in the recommended tasks. ENSET is the only supplier of trainer-technicians in Madagascar, even the Indian Ocean, and the gradual loss of players in the mechanical engineering sector would generate an imbalance in production which would also lead to severe shortages of teaching staff in training establishments users of the ENSET product (vocational training centers, technical and general colleges, ...).

In reference to Guy Brousseau [10] who showed that a didactic contract does only work with reciprocity determining the commitment between the teacher and the taught in their organizations. Our ambition is to deal with the problem from this perspective in order to better solidify the bilateral relationship between teachers and learners from the point of view of their commitments in the teaching-learning sequences. During the evolution of the history of technical drawing, many authors have invested in graphic representation: shape, size, position... [29,47,49] and as well as the description of the semic variables (signifier and signified) which reflects the technological aspect of the semiotic instrument [38]. Until the end of the 20th century, the authors work focused on writing and reading errors contributing to the development of the theory and practice of the technical drawing discipline over time. 
However, we are in the $21^{\text {st }}$ century, the materials and methods should be related to time. Currently, the collective practice of trainers remains traditionally and resistance to change can lead to various questions: how and how long does it really take, are institutions and communities ready, how and by what means? We are not able to discredit the conventional aspect of the teaching of technical drawing, but rather to take another look at the coherence of the combination of the digital aspect which is articulated with the virtual fact and that of conventional through a tool that seems more appropriate to the contemporary world. Davinia [15] stressed that training should meet the industrial need of its time, train workers and technicians qualified in their development leading to extensions and progressive job offers to the wish of the school also. It is time to review the more meaningful, adapted, and productive knowledge from a social point of view and the relevance of the program in the disciplines we want to promote. World has changed and this change forces us to followits reflect in all directions or activities that we would like to develop.

Many collaborators pointed out during the exchanges two main causes related to the context: lack of technology in teaching-learning, and the irrelevance of technical communication language caused by the insufficient scientific level of certain trainers in corrupt profit, when recruiting civil servants (disruption of formal knowledge caused by a political impact), examples: language difference between collinear and parallel; orthogonal and perpendicular; ambiguity between frontal plane and standing plane, even other projection planes; confusion in the sense of perspective (axonometric, isometric ...) and many others. These errors come in various forms and they also generate obstacles, since the informal knowledge acquired will take the place of a justified acquisition or good information in the memory of the recipients (learners).

With regard to these incidents, we propose a conceptual framework for the presentation of a virtual space object which will certainly meet the collective expectation from the point of view of transformation of a space object in a two-dimensional graphic space and will also provide the actors a descriptive reflection of the function of each system element inducing good mastery at the technological and geometric levels.

The virtual systems developed in animation modes (kinematic, dynamic, and exploded) are transformed into a video file, then distributed in the learner's mails. Subsequently, the parts forming the system in question are also sent in three-dimensional rendering mode before the learning sequences. The teacher becomes a moderator in front of the learners who are in the re-freezing phase and are committed to the development of their spatial capacities and, in this pragmatic and playful aspect, a socio-emotional climate inducing a co-construction of spatial thought of the population herself. The presentation of a spatial object directly in the graphic space (two-dimensional) seems less explanatory, except for those who have already been initiated in the previous classes, not only in the layout of views according to American or European standards, but also to the scale of semantic variables of the semiotic instrument (fig.1).

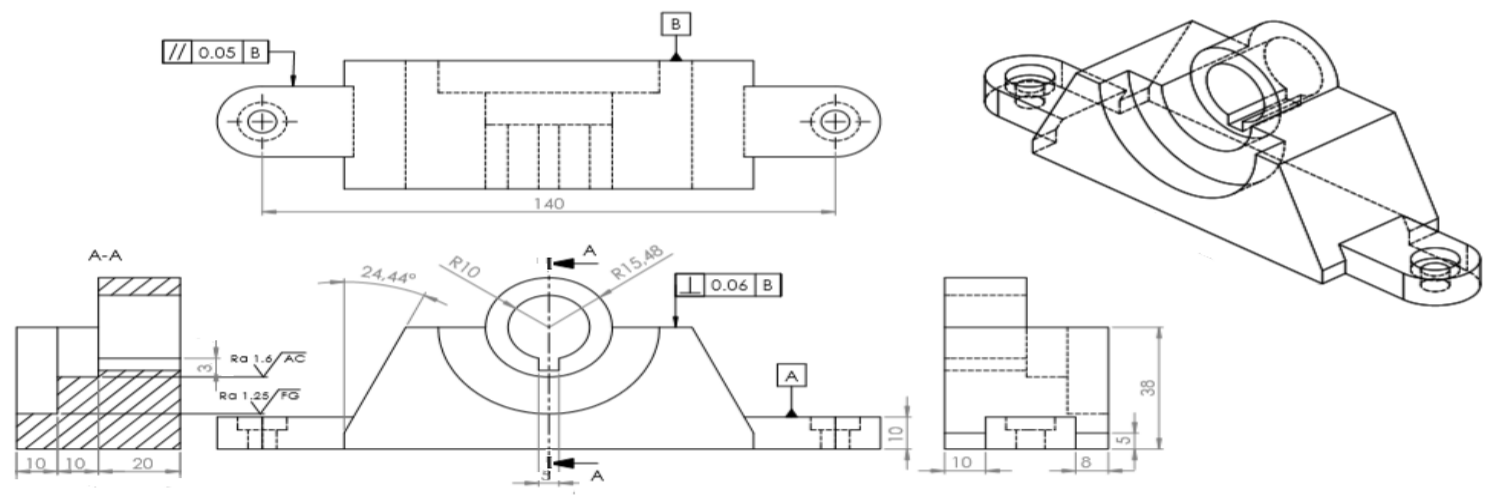

Figure1. Graphic representation of an object: definition drawing of a finished product starting from a perspective, a part called stand

Source: Laboratoire de Mécanique et de Métrologie LMM, ENSET, Antsiranana University, Madagascar

The conventional aspect of learning to draw is based on the knowledge of the graphic arrangements of the views of an object or from the available views to a reality or perspectives. However, the ambition of the new concept is to provide an introductory sequence in the presentation of the learning object, 
giving more meaning to the content through prior knowledge of the object and its role in the whole of its system other than of usual, for increasing the autonomy degree, confidence and insurance of the pupils during the requested tasks.

The approach is based on a demonstration of an animated and / or exploded system so that students can see the global and detailed description of the system and see one by one the parts that compose it. After that, the workpiece is marked and taken alone on the interface in rendering mode to see the exact description of the learning object. On reaching this point, a multitude of curiosities developing a socio-constructivist environment in the population and in this process that we can hope to overcome the diversity of obstacles linked to the category of errors [2].

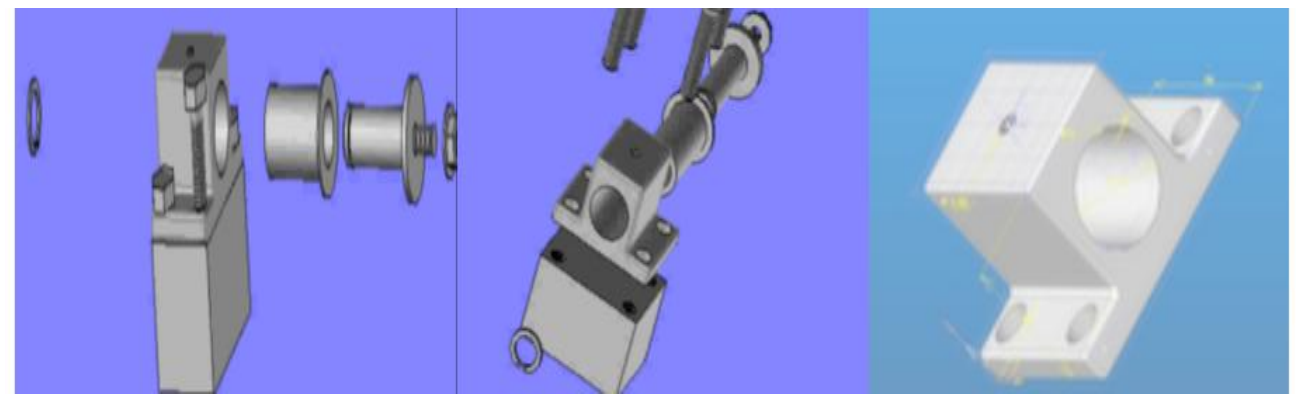

Figure2. Spatial representation model of virtual object starting from the whole, a part called bearing Source: Laboratoire de Mécanique et de Métrologie LMM, ENSET, Antsiranana University, Madagascar.

The virtual or real presentation of an object in perspective (cavalier or axonometric) (fig. 2), represents the subject more in its technological aspect and in this almost concrete reality conveys the flow of exchange between students towards a thought convention common for objective purposes and the purpose of this work.

\section{State of Play}

Our field of study is the pedagogical basis or common core (1st year) of the ENSET, which is home to the population conditioning the functionality of other institutions in the educational fields (vocational training centers, technical and general high schools, higher technology institutes,...). At the end of the 2016/2017 academic year, the class size $n=241$ and this had been increased during the 2017/2018 academic year and it reached 266. In the lack of infrastructure, the council School scientist has divided the pedagogical basis into two groups (Gr1: group 1 and $\mathrm{Gr} 2$ : group 2). The two groups have three subgroups respectively, so we have six subgroups in total (Gr11, Gr12, Gr13, Gr21, Gr22 and Gr23).

The table opposite shows the enrollment of each group and subgroup of the population in the last two university years.

Table1. Workforce in the groups and subgroups of the pedagogical basis at the ENSET (a): academic year 2016/2017; (b): academic year 2017/2018.

\begin{tabular}{|c|c|c|c|c|c|c|c|c|c|c|c|c|c|}
\hline Groups & \multicolumn{3}{|c|}{ GR1 } & \multicolumn{3}{|c|}{ GR2 } & Groups & \multicolumn{3}{|c|}{ GR1 } & \multicolumn{3}{|c|}{ GR2 } \\
\hline \multirow[t]{2}{*}{ Subgroups } & $\mathrm{Gr}$ & $\mathrm{Gr}$ & $\mathrm{Gr}$ & $\mathrm{Gr}$ & $\mathrm{Gr}$ & $\mathrm{Gr}$ & Subgroups & $\mathrm{Gr}$ & $\mathrm{Gr}$ & $\mathrm{Gr}$ & $\mathrm{Gr}$ & $\mathrm{Gr}$ & $\mathrm{Gr}$ \\
\hline & 11 & 12 & 13 & 21 & 22 & 23 & & 11 & 12 & 13 & 21 & 22 & 23 \\
\hline $\begin{array}{l}\text { Numbers } \\
\text { subgroups }\end{array}$ & 40 & 40 & 40 & 41 & 40 & 40 & $\begin{array}{l}\text { Numbers/ } \\
\text { subgroups }\end{array}$ & 45 & 45 & 44 & 44 & 44 & 44 \\
\hline Total (n) & \multicolumn{6}{|c|}{241} & Total (n) & \multicolumn{6}{|c|}{266} \\
\hline
\end{tabular}

(a)

(b)

Source: Main secretariat of ENSET, Antsiranana University, Madagascar.

ENSET has four teachers who insure technical drawing. We analyzed the syllabus and the relationship with the academic and ministerial reference, in order to better focus on the teacher-student framework and action and to consider a contribution that could bring not only a curriculum innovation, but also a modeling of the concept of teaching scientist in the new era.

\section{THEORETICAL FRAMEWORK}

Technological didactics does not yet seem to have emerged in the context of active research, particularly in the field of technical and professional education. However, professional training is 
developing, and this generally remains in empiricism, and the technicality of the art of transfer remains in second position.However,if we really want to encourage the appropriation of the scientific concept, it is necessary that the trainers master the theories and foundations of the art of teaching so that they can invest in their sequence a technological design approach to initiate a link between science and technology [47].

In the conquest of the causes of obstacles in the teaching of technological sciences, reviews of related work on which pedagogical, didactic and epistemological theories and practices are based is necessary in order to illuminate the conceptual framework. From the point of view of a broader conception of drawing, it is advisable to approach the three conceptual fields (technology, space and code or semic variables) to the magnitudes of technological significance [40]. In the geometric analysis process, the graphical aspect intervenes, and the problem is not only spatial, but it is also based on semic variables favoring the description of all geometric specifications of the object in semiotic instruments.

Bessot[8] evoked in her treatise on the geometry and trade of the building, the tasks in constructions depend on the reading of plan and this indicates than the technicians should have certain knowledge in mathematics, in particular Euclidean and descriptive geometries. The author also requested that the teaching of drawing be carried out in the workshops.

Within the framework of the transposition of geometrical knowledge, Rabardel[40] took up the proposal of Fassina[49], which is articulated on a reinterpretation of the results by referring to Piagetian works on the representation of spatial object. The author concluded with two strategies (figurative and operative) and reconfirms these conceptual aspects leading to discernment and identification of the production of the object by the subject. The author also requested the use of the semiotic dimension influencing the geometric and technical characteristics of the object in order to give more clarification on the representations the semic variables (signifier and signified) of the instrument in its technological aspects.

Technical drawing is an art of imagination, of thought and represents a universal aspect from the technological and scientific point of view. It is from drawing than experimental work can be set up: exploration, presumption, and construction, as Chaachoua [12] said. In this point of view, the author confirmed the existence of double function of the drawing in the resolution of the plane geometry problem by quoting Bkouche [9]. If we are interested in pragmatic aspects in the logical object representation context, Baldy and Chatillon [7] treated a problem of a real object as an educational model to compare the drawing of volume in perspective, the authors observed than the learners badly exploited the presence of the material in their activity. If the representation of the object appears in a semi-concrete, logical or virtual way, errors are less frequent and will be translated into representative skills according to the demand or the objectives to be achieved. Perception is also supported by the configuration of the spatial aspects of a space object [37,42]. Regarding this perception, Davinia [15] contributed to this perspective by using a digital representation environment to make her activity more fun and attractive.

Since 1984, some authors have proposed studying the role of a computer environment linked to the geometric construction profession [6,12]. It is a computer transposition, a spatial and computerized geometrical model favoring the widening of the fields of interpretation and its relationship with drawing, on the one hand, and of analyzing the construction problems of the computer environment, on the other hand, in order to better respond to the coexistence of certain criteria related to the computer environments and construction problems. It is requested to consider the perfection of the interface from the point of view of the internal universe when choosing the learning simulator, otherwise this choice could cause another obstacle related to the content or the interface.

In professional life, technical drawing presents many bases for conceptions, if the term conception is mentioned, this could be articulated in its derivatives (modeling, simulation, optimization...), as Tourpe (2004) said citing Ludi ( 1989) than drawing is a tool in various design operations, in all disciplines dealing with the construction and representation of space. The status of computer-aided drawing in construction is not intended to change or replace the conventional appearance of the instrument, however, it acts as an auxiliary. In addition, the use of computer-aided design (CAD) also offers a systemic representation of an object before birth. CAD will not only be able to transform the three-dimensional object into a flat graph or vice versa, but it will also be the subject of powerful 
simulation, parametric calculations and even manage massive data in a whole of the compiled system. It is less frequent before the computer-aided drawing for financial reasons and the extent of the storage capacity requested from the compiler. However, computer-aided designtransposes evolutionary technology into the world of design with many players (designers, engineers, architects, etc.) in their trades [43].

We describe the power of a CAD simulator since the envisaged model is articulated in the virtual concept of spatial object in order to provide an element of response to the context of epistemological obstacle which slows down the transfer of cognitive data. The object of this model is to find an element carrying knowledge from one or more perspective views (cavalier or axonometric) of an object and its role in the whole of its system. We emphasize than the use of the simulator is not for the purpose of teaching CAD to learners, but for modeling the educational grain through a didactic tool so the object treated is more pragmatic.

With reference to the conceptual framework, Davinia was doing a more innovative experience in teaching technical drawing. Its purpose is to provide an additional tool for students in learning technical drawing in compulsory school. The author has created a learning sequence in a computer room so than learners are directly involved in the notion of spatial vision and mental construction of a volume, with the aim of approaching their learning through another tool that seems more suited to the contemporary world. He proposed an e-action model in the learning sequences in order to create a more playful, recreational and socio-emotional environment, taking advantage of the stage or phase of accumulation of learners with various tendencies: watching, thinking, manipulating, exploring, identifying, transform, build, create, suggest... during the recommended activities or tasks.

Many authors testify to the relevance of a meaningful and declarative task to learners in order to better remain in contextual didactic practice. At present, it seems than learners are asking for another methodological perspective, of pedagogical innovation in teaching and learning science and technology to make activities more recreational and socio-emotional $[22,34,44]$. Given the interests brought by technology in training, some authors suggest than the contribution to a situation can be triggered by collective work and maintained by cooperative learning. The works carried out by Lacasse and Barma[24], corroborate this perception which is in the conquest of integration of technology anchored on the practice and realization of the hands on type in learning and evaluation situations integrating work in class-workshop in science education. The teaching profession requires a perception of engineering in itself and its form changes a priori from one situation to another. The practitioner should be a little genius and designer of his own theory in his actions [30,32]. So, a practicing teacher should be both a technician and an artist in his organizations. Teaching should be supported according to the situation, activity, context, culture, and many other factors $[25,48]$, and for each question, a specific study proves necessary [14].

Regarding these reference frameworks, Davinia's approach seems more obvious and could provide an element of response to our remarks. This model also seems transferable across certain related disciplines, in both digital and conventional content so that learners can see more of the overall shape of the learning object, know its environment, its function and its transdisciplinary utility.

\section{Methodology}

With reference to the Piagetian and Vygotskian models in the interventions and mediations, our ambition is to render the regulatory function in the sense of communication and representation. The conceptual framework of the work is based on the perfection of the teacher in their profession in terms of efficiency inducing a significant effect in its production through research and practice in the field. This media conception often intervenes in the action research model in order to find a link for the conclusion of research in education and in educational activities. Usually, researchers often identify problems relevant to their projects and propose solutions that suit their models, but often recognized as inadequate and rejected by teachers in the field [20]. Many authors have dealt this linkage problem $[1,3,11,18$,$] and they have suggested than actors in the field should be informed and supported to$ understand problematic research incidents related to educational practice. They also recommended the solutions proposed by researchers should also be tested in the field.

From a typological point of view, Lenoir [28] cited the classifications of research which supports the conceptual arguments brought by other authors $[19,26,46]$ to discern theseresearches scientifically. 
In this context, Van der Maren raised fourteen types of research from the classification point of view, with some or more criteria. However, each type of research requires not only reviews or analyzes of methodological processes, but also depends on the research questions, situation and intended ends of the research project. Considering the typological scope of the research, after the literature reviews, our recognition is based on action research, because of its collaborative aspect towards researchers and practitioners in the field. Lenoir et al. (2008) mentioned two types of action research (functionalist intervention research and action research with political stakes). Both types could be adopted, but it takes enormous time, because the change is radical. In this article, we first deal with the case of functionalist intervention which relies incessantly on a pragmatic action in the hope of having a more significant change in the learning system.

In reference to action research,Lewin [31] evoked support for transformation with the effects of variable forms of social action, and John Dewey pointed out the insufficient link between researchers and practitioners in the field. Many authors have cited the history of major moments in the evolution of action research [17,23] from 1946 to date [21]. However, the goal always converges towards collaboration between researchers and practitioners in the field. In this perspective, researchers become practitioners and practitioners become researchers and in this fraternal, scientific, and sociocultural appearance in the interest of a common objective than action research really brings about research action.

The methodological process of this work is based on two approaches, with the aim of referring to the mixed research method. The first is based on reflections and exchanges between the technicians responsible for the discipline: technical drawing, and also a certain number of learners, like a holistic inductive approach with the aim of having qualitative data (ideas during exchanges) which materialize the situation in the direct understanding of the phenomena and marking an index of will and cooperation between the actors involved. After the discussions (Madagascar-Canada), the main lines of the ideas brought out can be summed up in the following five axes: relevance of the course; insufficient practices; need to modernize activities; use of technology in teaching-learning; and updates of trainers knowledge. In the light of the technological emergence, our ambition is to find a material of conception and development of thought adapted to the contemporary era. After reviewing the ideas emerged during the discussions, the most striking and iterative are modernization and the use of technology in activities.

The second approach is based on a hypothetical deductive model in the interest having quantitative data. We have a logbook, for monitoring elements (individuals) in samples during the intervention process (production, acquisition, time allocated...), and the names of students will be kept anonymous to preserve their person right.

Samples were taken before, during and after the testing of the new device which is based on the accuracy of its prospective aspect which is based especially on observable facts inducing theories during learning by means of computer science and that the computer is no longer new hardware, but an auxiliary tool for mediating all disciplines.

These data are controlled measures of the performance of the individual during activities according to two variables (scores and production time). The measurements were made in three phases, the first concerns a sample in event the activity remained in its conventional aspect. The second is a measure of a temporal media nature anchored on an abundance of tasks and support for learners towards justified knowledge (adjustment of theorems, laws of projections, ...). Finally, the last is the data collection phase after the effective integration of the new concept which is based on a Vygotskian model through the digital technology, the objective of which is to provide an element of response both didactic and pedagogical certainly inducing a collective reflection towards the program and the education policy of the country.

Exchanges with internal and external actors reveal a meditative urgency between the relevance of the program and the accompanying technology. As a testimony to the sustained conceptual efficiency, researchers in the department of studies on teaching and learning of the Faculty of Education Sciences of Laval University in Canada, confirmed that the science and technology should no longer be separated to keep mutuality between them during its evolution. 
The implementation of the new concept sparked our ambition to use the simulators available in the ENSET mechanics and metrology laboratory. Among them, Topsolid occupies less memory space and simpler to use provided with a combination of many predefined tools in design option.

From the point of view of measurement-evaluation-decision, its application is rarely found universal, but depends on the situations, the criteria or scales of judgments vary from one case to another depending on the objective purpose of the work. However, measurement and evaluation still play an important role in decision-making through its justification characters [41]. The data were processed and tested using a statistical tool to confirm the techno-didactic, methodological, and conceptual performance of the device. Currently, many methods exist from the point of view of statistical processing, but the choice is always imposed on the quality of the data and the situation studied.

Fluctuations in the values taken can lead to divergence and these values no longer follow a distribution of the normal law. However, hypothesis tests offer dimensions of parametric comparisons or not parametric. With regard to existing treatment models, the Mann-Whitney method can meet our needs, from the point of view of treatment independently of parametric variables, but only relies on the notion of ranks and signs like Wilcoxon's, hence the name: Mann-Whitney-Wilcoxon test.

To follow up on the methodological process, the hardware (processing tool) adopted is the XLstat software, due to its simplicity, flexibility and power of the algorithm. The environment of the tool consequently meets the scientific criteria requested and the representative curves before, during and after the testing of the device will be presented and discussed in the following paragraph.

\section{RESUlTS AND DisCUSSION}

In this presentation, the data exchanged with the responsibles is retained as an element of confirmation of the presumed assumption of departure. These data represent a multitude of expressions and which can be summarized in five main axes as we have already pointed out previously, and these resulting ideas remain as a confirmation beacon of the initial hypothesis, on the one hand, and a real demand of the situation, on the other hand. However, the quantitative data are obtained by direct observation of the learners in a learning situation and they represent the evolution in the marks and times of execution or production of each activity.

In general, the variation curves behave like continuous sinusoidal progressive and sometimes regressive functions. In these results, the word "before" in the measures indicates the conventional mode or aspect of the educational approach used in the activities to which all the sub-groups are concerned before the testing of the new device. The word "during" indicates the value of time after the first measurement and followed by a certain mediation (overabundance of tasks, adjustment of theorems or laws of projections, ...). This interval represents a transition phase which seems important, since it describes the presence of impulse or not of the variables and as well as the performance of the elements in the samples. In this part, we have not only adopted the conventional characteristic in all these forms, but we have also integrated a glut of tasks to confirm or not the insufficiency of the tasks in the sequences of learnings answering one of the problems. underlined during the exchanges In these figures or in the text, we find the word " after", this word designates the position with which the pulsations of the variables are more confirmative after the application of the new learning device.

Before the implementation of the new concept, the function curves of the notes and times of Gr11 remain in the interval of] 8, 10 [, this indicates the conventional aspect of the approach or the overabundance of tasks in activities does not stabilize more the cognitive aspect of the knowledge taught (fig.3.a).
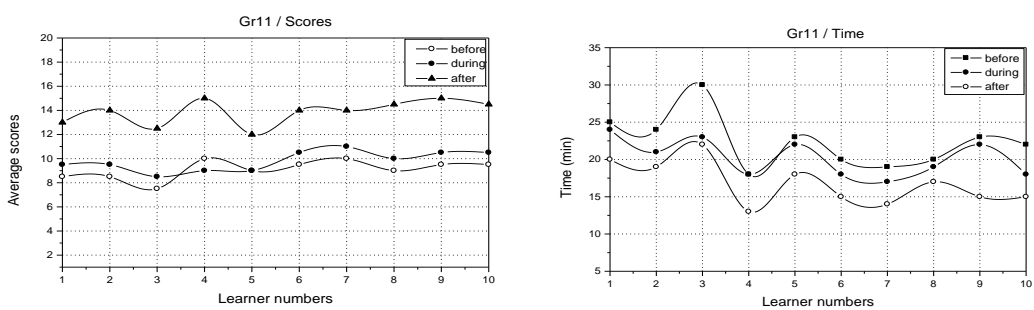

(a): notes according to the learner'snumbers; (b): time according to the learners' numbers.

Figure3. Variations of the notes and production times of the elements of the subgroup Gr11 
The note functions are presented differently from the time distributions of productions, but the difference between the two curves confirms the effect of the interventions during the second sampling phase. We would also like to confirm these observations through the distribution of these variables in another subgroup.
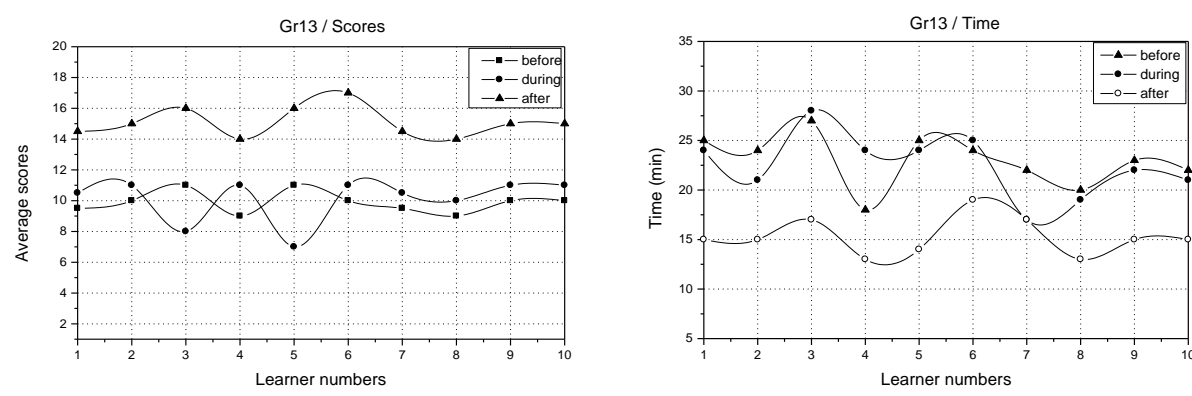

(a): notes according to the learner's numbers; (b): time according to the learners' numbers.

Figure4. Variations of the notes and production times of the elements of the subgroup Gr13

In Figure 4, the shapes of these curves are very close to those of the previous ones and the arrangement of the notes is in the range of] 7, 11 [, before and during the process. However, after the implementation of the new system, these values remain more significant (fig.4.a). The impulsive nature of the variable in the elements of the sample confirms the effectiveness of the tool and the scores are very efficient, the lower value is around 14 and the upper value is 17, taking into account a open interval. This observation is thus confirmed in the temporal evolutions of productions (fig.4.b).
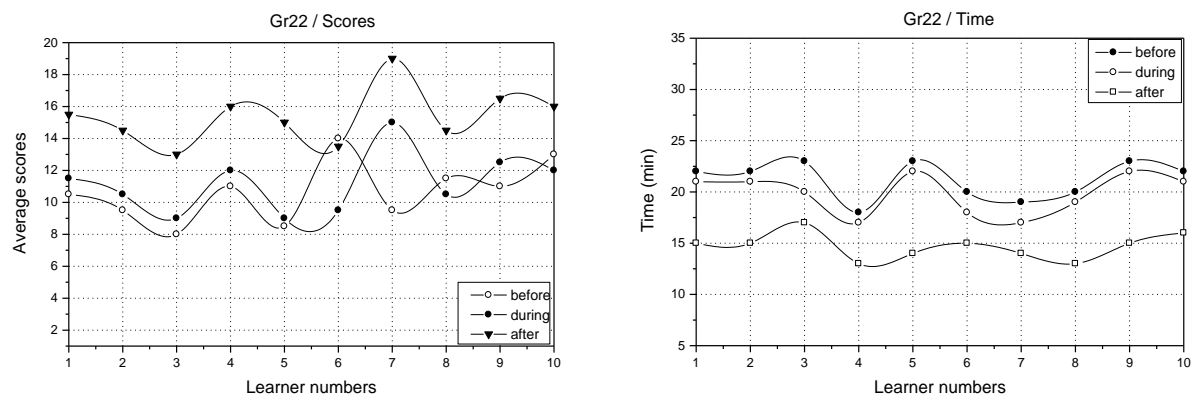

(a): notes according to the learner's numbers; (b): time according to the learners' numbers.

Figure5. Variations of the notes and production times of the elements of the subgroup Gr22

Variation curves (notes and times) before and during the process sometimes present themselves in an alternative and tangential way and their meanings seem reluctant to keep or reject the initial hypothesis. Some of the elements are in optimal time, as in the case of pupils $n{ }^{\circ} 7$ and $n{ }^{\circ} 4$ in figure 1.b, but their notes dropped from 10 to 8 for $\mathrm{n}^{\circ} 7$ and from 10 to 9 for $\mathrm{n}^{\circ} 4$ (fig.3.a). Given these observations, the second sampling phase is of no interest from the point of view of student performance. However, the representative curves of the variables after testing the new approach showed a good difference in the observed sample (fig.5.a \&5.b). The distributions of the notes are found in the intervals of] 12, 17], for group 1 (fig.4.a), against] 13, 19], to group 2 (fig.5.a). Thereafter, most of the elements are found below the average time (20 minutes) which is assumed to be an optimal time for each learning module (fig.6.a).
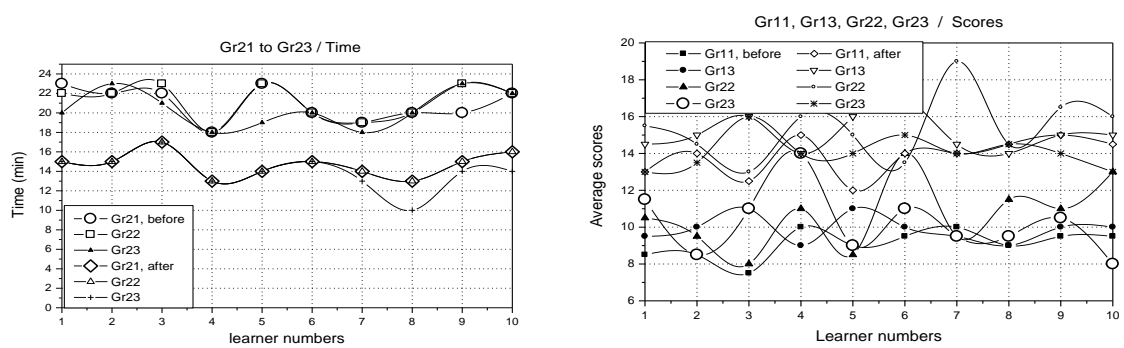
Study and mitigation of epistemological obstacles in the technological disciplines of higher education in Madagascar: Case of industrial technical drawing

(a): time before and after, according to the learner's numbers, subgroups Gr21-22-23; (b): notes before and after, according to the numbers of the learners, sub-groups Gr11-13-22-23.

Figure6. Evolution of time and notes of the elements in certain subgroups

The concept regulates the progression of notes and the regression of production time and this contributes to $25 \%$ of the performance, both individual and collective.

Regarding these variables, is there a positive or negative correlation between the notes and production times of the elements? We know the distribution time is regressive compared to than of the notes, but this observation marks a performance over production time, and this can be interpreted as a progression over time and dependence between the variables. The progression over time does not necessarily imply a constant progression in the notes if the learner is still in a stage of unconscious competence, however, this part is the subject of another article since it is advised to move to another statistical dimension (correlation / association).

The representative curves of the variables on the third samples marked a performance in engineering training, temporality, and this would imply added value, which is often ranked higher in order or classification, quality. In view of these observations, the data obtained on the third samples seem more significant in all the samples. Our interest is to keep the method, since the results are confirmatory, but we still had to look at a statistical dimension on which the consistency of validity of a scientific decision-making rest. In this context, the selected theory and material have already been mentioned in the previous methodological process.

The Mann-Whitney-Wilcoxon test is ultimately used to compare the mean of the samples or variables [33]. However, it does not study the values of the variable, but the ranks of these values. In a Wilcoxon test, the null hypothesis states the rows mix homogeneously between the samples, but the alternative hypothesis is always based on a difference in position between the distributions of the variables in the samples tested.

We also adopt a level of significance $\alpha=5 \%$ in the calculations and this is classified in the unilateral tests. Thanks to XLstat, we no longer need to calculate the sum of the ranks, the Mann-Whitney test statistic $\mathrm{U}$ or a Gaussian approximation of the law of test statistic Z, but the predefined statistical models in the XLstat allow us to facilitate tasks, if the data is well organized in a spreadsheet. We took $\mathrm{D}=2.0$, the difference between the samples tested, with respect to the differentiated distribution of the alternative hypothesis. After the calculations, the mean value of the statistic p-value $<0.0001$ and if $p$-value $<\alpha$, the null hypothesis must be rejected and we keep the alternative hypothesis which supports the difference in position of the distribution of the variables between the samples (pre / post) of each sample of the population. Several data have been tested through this model and the results have confirmed the effectiveness and relevance of the numerical approach to socio-emotional behavior in learning technical drawing and that this seems transferable not only in the technological disciplines within the establishments of higher education, but also in basic education and post basic as well as in the technical and general educations.

\section{CONCLUSiON}

This paper presents the results of the measurements in the context of an epistemological obstacle in the teaching-learning of technical drawing which curbs the affection inducing the learner's failure. In this context lies the reason the loss of choice towards the mechanical engineering sector of ENSET, Antsiranana University, Madagascar.

Technical drawing is a universal instrument, but its form changes a priori according to the fields in which it intervenes. In this work, we provide an element of answer to the obstacle questions and the material adapted to the population involved. Many authors have invested in the graphic transformations of a spatial object, decoding the semic variables of a semiotic instrument in its technical aspect or other exploratory perspective which is part of an epistemological current. However, these perceptions require an auxiliary element linked to time. We put an emphasis on time, since the material in question depends on its time. Regarding all the theories cited, this work refers to 
a typology of action research in the hope of having a more solid link between researchers and practitioners in the field. From a methodological point of view, we have adopted two approaches: exchanges with technicians in the field, managers of certain teaching units, internal and external researchers and as well as a certain number of learners to get to know the main lines of causes and effects, to understand the direct reality of the situation studied and to have various expressions, highlighting the tools and methods than can contribute to the desired change. The second approach is based on the direct observation of the individual in a learning context, to verify his cognitive performance, to contribute to the construction of their knowledge and also to the development of their competence during activities according to the three modes opted.

The sample data are reorganized in a spreadsheet, and the representative curves of the variables were obtained with the Origin software. After obtaining the evolution curves of the variables, a hypothesis test between the data collected was carried out to highlight the scientific nature of the approach and thus prove the consistency of the prospective effect of the tool we would like to introduce.

In short, the educational innovation provided reflects not only the knowledge taught (nature, structure, properties, ...), but also a new perception and observation of the learner in the cognitive current [47] through the new era, and in the digital conviviality reflecting the contemporary world, in practices and organizations [15] which should prompt a reorientation of the national educational policy in force in the face of technological advances and its absence or delay in training, on the one hand, and multidisciplinary scientific productions than would contribute to institutional developments and to the teaching community, on the other hand.

\section{REFERENCES}

[1] Asbury, C. A. (1975). Why Educational Research is of Limited Use to the Community. ERIC, Ed 103398.

[2] Astolfi, J. P. (1997). Les huit types d'erreurs recensés par Astolfi. Spotted at http://sylvain.obholtz.free.fr/cariboost_files/les_208_20errreurs_20astolfi.pdf.

[3] Avanzini, G. (1978). L'attitude du corps enseignant face à la recherche. Les sciences de l'éducation, 1, 65- 78.

[4] Bal, J., Rabardel, P. et Vérillon, P. (1984). Présenter la géométrie du dessin technique. L'apprentissage de la géométrie du dessin technique : des constats d'échec et des moyens de réussite, 13- 47.

[5] Balacheff, N. (1994a). La transposition informatique note sur un nouveau problème pour la didactique vingt ans de didactique des Mathématiques en France. Grenoble : La Pensée Sauvage Editions.

[6] Baldy, R. et Chatillon, J.-F. (1992). Comparer des dessins de volumes en perspective cavalière. Tréma, (2), 15- 27.

[7] Bessot, A. (2009). Géométrie et métiers du bâtiment. HAL, archive ouverte. 1- 12. Spotted at https://docplayer.fr/25223363-Annie-bessot-hal-id-hal-https-hal-archives-ouvertes-fr-hal.html

[8] Bkouche, R. et Soufflet, M. (1983). Axiomatique, formalisme et théorie. Bulletin Inter-Irem « Enseignement de la géométrie », (38), 3- 24.

[9] Brousseau, G. et Balacheff. (1998). Théorie des situations didactiques: Didactique des mathématiques 1970-1990. La Pensée Sauvage, Grenoble.

[10] Brown, P. (1976). Educational Research and Practice: A Literature Review. Journal of Teacher Education, 27, 11- 19.

[11] Chaachoua, A. (1997). Fonctions du dessin dans l'enseignement de la géométrie dans l'espace. Etude d'un cas : La vie des problèmes de construction et rapports des enseignants à ces problèmes. Thèse de doctorat. Université Joseph Fourier, Grenoble, France.

[12] Chevalier, P. (1992). Nouvelles technologies éducatives et situations pédagogiques. EPI-INRP.

[13] Chevallard, Y. (1994). Nouveaux objets, nouveaux problèmes en didactique des mathématiques. Vingt ans de didactique des mathématiques en France, 313- 320.

[14] DaviniaLagoa, A. P. (2008). Le dessin technique: Origine et avenir au cycle d'orientation. IFMES. Genève.

[15] De Ketele, J. et Roegiers, X. (1991). Le recueil d'informations, l'évaluation, le contrôle, la mesure, la recherche : Serviteurs et maîtres. AFIRSE, Les évaluations. Toulouse : PUM, 143- 161.

[16] Dubost, J. (1984). Une analyse comparative des pratiques dites de recherche-action. Connexions, 43, 9- 28. 
Study and mitigation of epistemological obstacles in the technological disciplines of higher education in Madagascar: Case of industrial technical drawing

[17] Farell, J. B. (1970). Research for Teachers (Sydney: Angus and Robertson).

[18] Gauthier, C. (1997). Pour une théorie de la pédagogie: Recherches contemporaines sur le savoir des enseignants. De Boeck Supérieur.

[19] Goyette, G., Villeneuve, J. et Nézet-Séguin, C. (1984). Recherche-action et perfectionnement des enseignants : Bilan d'une expérience. Sillery : Presses de l'Université du Québec.

[20] Guay, M.-H. et Prud'homme, L. (2018). La recherche-action. Dans La recherche en éducation. Sous la direction de Thierry Karsenti et Lorraine Savoie-Zajc (p. 235- 267). Les Presses de l'Université de Montréal.

[21] Juuti, K., Lavonen, J., Uitto, A., Byman, R. and Meisalo, V. (2010). Science teaching methods preferred by grade 9 students in Finland. International Journal of Science and Mathematics Education, 8(4), 611- 632.

[22] Kemmis, S. and Taggart, M. (2002). R. 1988. The Action Research Planner.

[23] Lacasse, M. et Barma, S. (2012). Intégrer l'éducation technologique à l'éducation scientifique : Pertinence pour les élèves et impacts sur les pratiques d'enseignants. Canadian Journal of Education, 35(2), 155- 191.

[24] Lave, J. and Wenger, E. (1991). Situated learning: Legitimate peripheral participation. Cambridge universitypress.

[25] Lefrançois, R. (1991). Dictionnaire de la recherche scientifique. Lennoxville, Québec : Éditions Némésis.

[26] Lenoir, Y. (1993). Entre Hegel et Descartes : De quels sens peut-il être question en didactique. Sens des didactiques et didactique du sens, 29- 99.

[27] Lenoir, Y., Hasni, A., Lacourse, F., François, L., Philippe, M. et Zaid, A. (2018). Guide d'accompagnement à la recherche. Un outil de réflexion sur les termes et expressions liées à la recherche scientifique (Cursus Universitaire). Québec, Canada.

[28] Leplat, J. et Petit, R. (1965). Relations entre le dessin et les exercices pratiques dans l'apprentissage d'un métier manuel. Bulletin du CERP, 14(1- 2), 117- 124.

[29] Lesne, M. (1984). Lire les pratiques de formation d'adultes : Essai de construction théorique à l'usage des formateurs. Edilig.

[30] Lewin, K. (1946). Action research and minority problems. Journal of social issues, 2(4), $34-46$.

[31] Malglaive, G. (1987). Lire les pratiques de formation d'adultes : Essai de construction théorique à l'usage des formations. Spotted at https://www.persee.fr/docAsPDF/rfp_0556-7807_1987_num_78_1_2417_t1_ 0112_0000_2.pdf

[32] Nachar, N. (2008). The Mann-Whitney U: A test for assessing whether two independent samples come from the same distribution. Tutorials in quantitative Methods for Psychology, 4(1), 13 - 20.

[33] Osborne, J., Simon, S. and Collins, S. (2003). Attitudes towards science: A review of the literature and its implications. International journal of science education, 25(9), 1049- 1079.

[34] Pair, C. (1987). Informatique et lutte contre l'échec scolaire. Psychologie française, 32(4), 293 - 299.

[35] Piaget, J., Inhelder, B., Langdon, F. J. et Lunzer, J. (1956). La Représentation de L'espace Chez L'enfant. The Child's Conception of Space... Translated... By FJ Langdon \& JL Lunzer. With Illustrations. New York; Routledge et Kegan Paul: London; printed in Great Britain.

[36] Rabardel, P, Rak, I. et Vérillon, P. (1988). Machines-outils à commande numérique. Paris: Approches didactiques INRP.

[37] Rabardel, Pierre. (1982). Influence des représentations préexistantes sur la lecture du dessin technique. Le travail humain, 45(2), 251.

[38] Rabardel, Pierre. (1989). Recherches en psychologie et en didactique : Un exemple d'interactions dans l'enseignement du dessin technique. Revue française de pédagogie, 89, 55- 62.

[39] Scallon, G. (2004). L'évaluation des apprentissages dans une approche par compétence. Édition de renouveau pédagogique, p. 242. Canada.

[40] Shepard, R. N. and Metzler, J. (1971). Mental rotation of three-dimensional objects. Science, 171(3972), 701- 703. Spotted athttps://doi.org/10.1126/science.171.3972.701.

[41] Tourpe, A. (2004). Le Dessin Assisté par Ordinateur dans la formation des ingénieurs : Proposition et évaluation d'environnements d'apprentissage. Presses univ. de Louvain, p. 268.

[42] Urgelli, B. (2008). Éducation aux risques climatiques. Premières analyses d'un dispositif pédagogique interdisciplinaire. Aster.

[43] Van der Maren, J.-M. (1996). Méthodes de recherche pour l'éducation. Presses de l'Université de Montréal et de Boeck. 
Study and mitigation of epistemological obstacles in the technological disciplines of higher education in Madagascar: Case of industrial technical drawing

[44] Van der Maren, J.-M. (2003). La recherche appliquée en pédagogie : Des modèles pour l'enseignement. De Boeck.

[45] Vérillon, P. (1996). Approches psychologiques et didactiques en technologie: L'exemple du dessin technique. Institut National de Recherche Pédagogique, 22, 127- 147.

[46] Vygotsky, L. S. (1962). Thought and language (E. Hanfmann\& G. Vakar, trans.).

[47] Weill-Fassina, A. (1973). La lecture du dessin industriel: Perspectives d'étude. Le Travail Humain, 121- 139.

\section{AUTHORS' BIOGRAPHY}

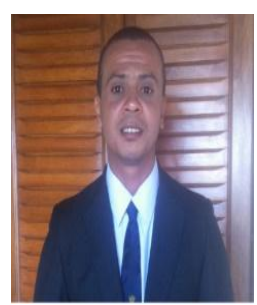

Dr. Ulrich Canissius, studied at Antsiranana University, around factory mechanics and fluid mechanics, energy option. In 2018, postdoctoral fellow in education sciences at Laval University, Quebec, Canada. Recently, he heads the civil engineering and metallic structure department to the ENSET School at Antsiranana University, Madagascar.

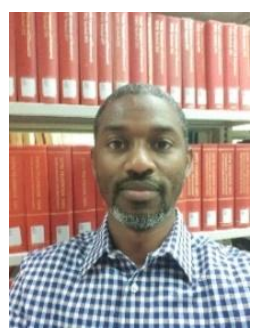

Dr. Abdoulaye Anne, is an Associate professor at Department of Educational Foundations and Practices at Université Laval. As an educational policy specialist, he is a researcher at the Center for Research and Intervention on Academic Achievement (CRIRES) and the Interdisciplinary Center for Research on Africa and the Middle East (CIRAM).

Citation: Ulrich Canissius, Abdoulaye Anne. "Study and mitigation of epistemological obstacles in the technological disciplines of higher education in Madagascar: Case of industrial technical drawing" International Journal of Humanities Social Sciences and Education (IJHSSE), vol 7, no. 12, 2020, pp. 75-86. doi: https://doi.org/10.20431/2349-0381.0712009.

Copyright: (C) 2020 Authors. This is an open-access article distributed under the terms of the Creative Commons Attribution License, which permits unrestricted use, distribution, and reproduction in any medium, provided the original author and source are credited. 